\title{
GEOMATICS TECHNOLOGIES IN THE FRAMEWORK OF MULTIDISCIPLINARY PROJECT FOR INTEGRATED MANAGEMENT OF CULTURAL HERITAGE SITES
}

\author{
C. Moise ${ }^{1}$, A.-M. Lazar², C. E. Mihalache ${ }^{1}$, L. A. Dedulescu², I. F. Dana Negula², A. Badea ${ }^{2}$, V. D. Poenaru², R. Moise ${ }^{1}$, A. R. \\ Ortan $^{1}$
}

${ }^{1}$ University of Agronomic Sciences and Veterinary Medicine of Bucharest - CM: cristimoise@yahoo.com, CEM: mihalachecristina19@gmail.com, RM: ruxandra.badea@gmail.com, ARO: alina_ortan@hotmail.com

${ }^{2}$ Romanian Space Agency - (andi.lazar, andreea.dedulescu, iulia.dana, alexandru.badea, violeta.poenaru)@rosa.ro

KEY WORDS: cultural heritage, remote sensing, digital reconstruction, conservation, nanotechnology, multidisciplinary

\begin{abstract}
:
Cultural heritage represents the link between past and present civilizations, contributing to the right appreciation of the presentday by understanding the historical evolution of different human communities that are shaping our world. Preservation of the cultural heritage and mitigating potential risks on invaluable artifacts or objectives is key to conserving the identity of present and future generations. Our complex project is dedicated to monitoring, conservation, protection and promotion of the Romanian cultural heritage. It addresses the challenge of better safeguarding the cultural heritage by developing a multidisciplinary approach. The combined use of Synthetic Aperture Radar and multispectral satellite imagery represent a non-invasive investigation instrument that enable multitemporal analysis, contributing with valuable insights regarding cultural heritage sites. Remote sensing techniques were used to generate geospatial products such as displacement maps, urban sprawl evolution maps, urban heat island maps and many more.

For protecting important artifacts, innovative recipes based on nanotechnologies were developed. In order to promote these artifacts, 3D photorealistic models were created using 3D reconstruction technology. For selected cultural heritage objectives, an integrated LiDAR aerial mapping system has enabled the creation of a high accuracy 3D model.

This paper illustrates how different technologies, ranging from remote sensing to nanotechnology, could be used for safeguarding and promoting the Romanian cultural heritage and represents a first step in establishing and consolidating a multidisciplinary team involved in this domain.
\end{abstract}

\section{INTRODUCTION}

The ongoing complex project dedicated to monitoring, conservation, protection and promotion of Romanian cultural heritage has the goal of bringing together various technologies from nanotechnologies to satellite imagery and close-range remote sensing.

The complex project is composed by 4 component projects P1: Monitoring of cultural heritage based on space technologies, P2: Nanotechnology - an innovative approach of developing materials and methods for cultural heritage safeguarding, P3: Integrated cultural heritage management (conservation, restoration and protection) and P4: Cultural heritage promotion based on modern digital reconstruction technologies.

For the project, several relevant test sites were selected, consisting of ancient roman and medieval objectives: Sarmizegetusa Regia, Ulpia Traiana Augusta Dacica Sarmizegetusa, Medieval Fortress of Deva, Magna Curia Palace, Corvin Castle, Roman Fort of Cigmau, Micia Roman Fort and Alba Carolina Citadel. All the above mentioned objectives are of a great national and international importance (Sarmiszegetusa Regia being part of UNESCO World Heritage). The objectives are situated in the historical region of Transylvania, a very important area which includes a large diversity of cultural heritage sites.

Cultural heritage $(\mathrm{CH})$ objectives are often situated in areas vulnerable to natural or anthropic hazards. Geospatial technologies are a powerful tool for monitoring cultural heritage sites in order to protect them from different types of hazards (Agapiou et al., 2015). Alongside the foreword mentioned objectives, tests were conducted on several artefacts from the same region in order to determine the best practices and methods to protect them from the environmental factors.

The main objective of the complex project is to integrate existing technologies to meet the real needs of archaeologists and safeguarding the cultural heritage sites listed in the project, starting with complex geospatial products and continuing with complex methods of conservation and promotion. This paper illustrates several multidisciplinary approaches for a complete management of the cultural heritage patrimony.

\section{COMPONENT PROJECTS}

\subsection{Project 1: Monitoring of cultural heritage based on space technologies}

The project focuses on monitoring the cultural heritage using advanced Earth Observation technologies such as Synthetic Aperture Radar (SAR) and multispectral imagery for creating a management plan for conservation of the objectives.

Every cultural heritage site included in the complex project, has unique challenges for conservation, therefore multiple types of monitoring methods were applied.

2.1.1 Persistent Scatterer Interferometry: Space-borne Interferometry is suitable for monitoring the cultural heritage buildings. The results obtained from this non-invasive method can improve cultural heritage management and alert the proper authorities in case of landslide emergency or prevent any other emergency cases. In this case study, the focus is on one of the cultural heritage objectives: Corvin Castel in Hunedoara, 
Romania. The Sentinel-1 mission is dedicated to environmental studies and security applications, monitoring of global landmasses, costal zones and shipping routes. Sentinel-1 has active imaging sensors which facilitate the clouds penetration and can acquire data independent of illumination, during day and night, independent of weather conditions, with the capability of continuous mapping the Earth surface with a high temporal and spatial resolution. Sentinel-1A was the first Synthetic Aperture Radar (SAR) satellite launched within the Copernicus programme, in April 2014, followed by Sentinel$1 \mathrm{~B}$ in April 2016, operating in C-band $(\lambda=5.6 \mathrm{~cm})$ and flying in an sun-synchronized orbit (Geudtner et al., 2014).

The satellites acquire data in 4 different modes: Interferometric Wide Swath (IW), Extra Wide Swath (EW), StripMap (SM) and Wave (WV). The data is available in 3 different processing levels: (i) Level-0 compressed unfocused SAR raw data, (ii) Level-1, generally Single Look Complex (SLC) providing the complex samples preserving the phase information and Ground Range Detected (GRD) focused SAR data, detected multi-look and projected, and (iii) Level-2 which includes data for Ocean Swell spectra. The data acquired by Sentinel-1 in IW mode, Level-1 SLC, with 12-day repeat cycle for each satellite (S1A \& S1B), is dedicated for Persistent Scatterer Interferometry processing.

SAR sensors utilize coherent signal with the capability of recording the amplitude and phase. One of the two components is more sensitive to the distance between the target point and the antenna, this being the phase component, consequently of this sensitivity vegetated areas are often affected by temporal decorrelation.

The pixels corresponding to stable areas can be analysed in case of ground motion through the phase history of each image used for the case study, these pixels therefore are called Persistent Scatterers.

Persistent Scatterers Interferometry (PS-InSAR) represents an advanced and complementary method to Differential SAR Interferometry (DInSAR), this technique requires at least two complex images acquired over the same area with the same sensor at different times or two sensors with the same characteristics for the calculation of the difference between the phase components, providing millimetric displacement measurements. In contrast with DInSAR, PS-InSAR analyses a series of SAR images, at least 20, in order to estimate millimetric displacement (Crosetto et al., 2016; Ferretti et al., 1999). PS-InSAR can be affected by geometric decorrelation, temporal decorrelation and atmospheric artefacts, although the technique is precise (Colesanti and Wasowski, 2006).

For the Corvin Castel objective the suitable monitoring technique for displacements measurements is PS-InSAR

For the processing stage, a number of 20 images acquired by Sentinel-1A descending pass, orbit 80, from March 2018 to October 2018 were used alongside 21 images from Sentinel-1B in ascending pass, orbit 29 acquired from March 2018 to October 2018. All the images were downloaded from Copernicus Open Access Hub that provides free and open access to Sentinel-1, Sentinel-2, Sentinel-3, and Sentinel-5P data. The images were processed with ENVI SARscape using the standard procedure, with the coherence threshold of 0.65 . The results of the processing phase were integrated and analysed in a GIS environment. Figure 1 presents the results of the PS-InSAR processing obtained for the Corvin Castel using ENVI SARscape software.

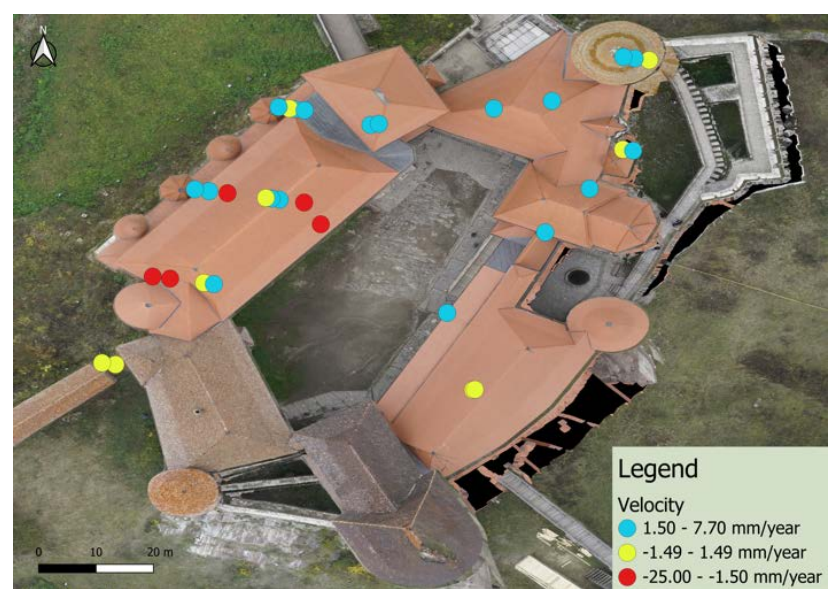

Figure 1. Monitoring displacements of the Corvin Castel using PSinSAR method

The displacements show positive values up to $+7.70 \mathrm{~mm} /$ year in the north-eastern part of the building and negative values on the west side expanding from -1.50 to $-25.00 \mathrm{~mm} /$ year.

In-situ investigation is recommended in this case, the building should be maintained under monitoring and the local authorities may consider a detailed investigation on the Castel structure and its surroundings.

2.1.2 Satellite Multispectral Optical Images: Satellite imagery can play a very important role in safeguarding the cultural heritage sites by providing a comprehensive image with variable temporal, spatial and radiometric resolutions, showing a complete image of the sites protected area and the surroundings (Diofantos G. et al., 2013; Tapete, 2018).

Analysis of the cultural heritage sites was one of the first uses of aerial images. The first images were taken in 1906 over Stonehenge using black and white film. The middle of the $20^{\text {th }}$ century was marked by the first use of multispectral sensors mounted on spaceborne satellite platforms. The new technologies allowed analysis in the area of buried structures by showing the differences in soil moisture and crop growth (Luo et al., 2019).

The increasing number of multispectral Earth Observation satellite missions, launched in the last decades, starting with ERTS 1 in 1972 (mission renamed in 1975 Landsat-1), provides a vast collection of images that covers the whole world. Free and open data policies granted access to a large collection of data for researchers, scientist, companies or enthusiasts. Nowadays, the access to satellite multispectral imagery is facilitated by large space data repositories containing data from missions like Landsat 1-8, Sentinel-2 and many other, providing unlimited access to data that spans from 1972 until present day. This allows the detection of long-term changes over vast areas in order to evaluate the potential hazards that can pose a threat to cultural heritage sites.

A step forward in space archaeology was in 1999 with the launch of Ikonos, the first commercial very high spatial resolution Earth Observation satellite (Diofantos G. et al., 2013).

A large number of algorithms were developed to take advantage of the multispectral data potential in order to asses multiple features of the Earth's surface. Various tests have shown that the analysis of products resulted from high resolution multi spectral imagery, such as False Colour Composites, Humidity Indices, Vegetation Indices, can indicate crop marks and revile the presence of buried structures 
(Agapiou, 2017; Agapiou et al., 2014). The most common indexes used for detecting archaeological crop marks includes near-infrared spectral band which is sensitive to vegetation growth.

Buried structures are detectable on the soil as areas with different content of humidity and regular patterns that do not match with the surrounding vegetation. These areas are related with shallower soil structures that inhibits vegetation growth and corresponds to positive structures. These effects are most visible on agriculture plots with homogeneous crops. Negative ancient structures, such as ditches or canals, are represented by regular pattern areas with an excess of humidity. These areas are more evident in periods with low quantity of precipitations. Detection of such patterns is easier for well-developed crops.

In the framework of the complex project, various methods of monitoring were used on multiple types of cultural heritage objectives represented by medieval castles, fortifications and ancient roman archaeological sites. The multispectral analysis was concentrated on the archaeological sites and their surroundings with very good results.

For the analysis of the vegetation in the areas of the monitored archaeological sites and their surroundings, False Colour Composites (FCC) were used by stacking Sentinel-2 atmospherically corrected images (Level 2A). Several band combinations were tested, the most useful was the NIR, R, G stack. In the case of Micia Roman Fort, crop marks were identified in the southern part of the site. As depicted in Figure 2 , patterns in the vegetation can be detected that matches with map information of ancient structures created with in-situ data Figure 3 (Oltean, 2007).

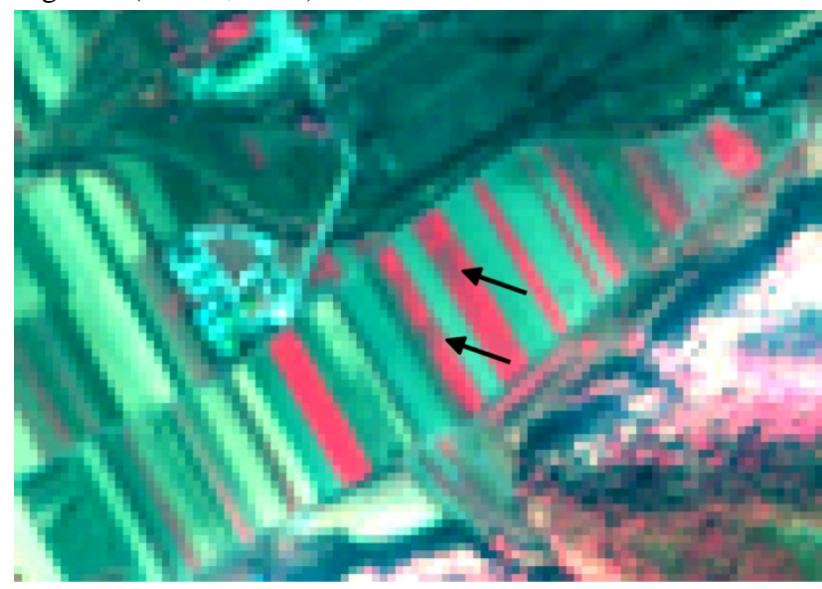

Figure 2. Sentinel-2 based FCC illustrating crop mark

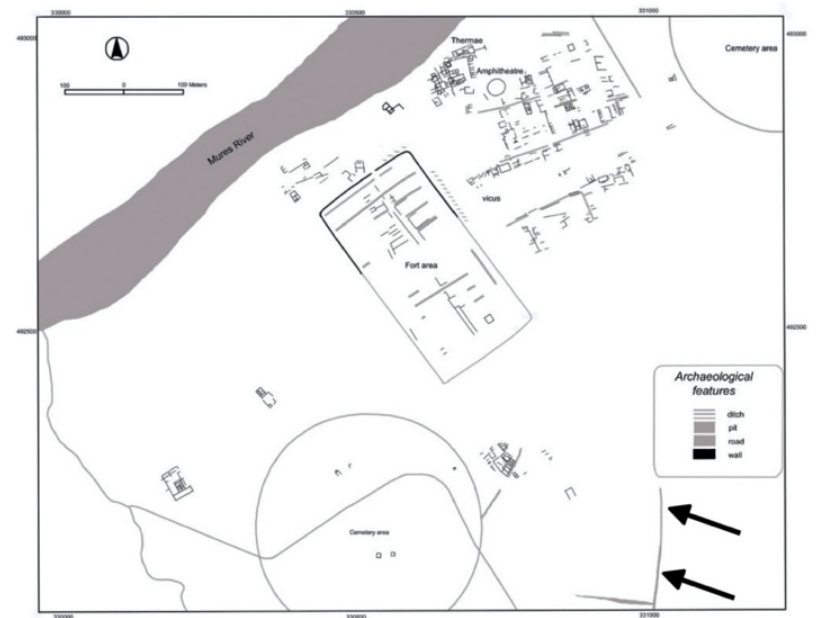

Figure 3. Map of the Micia Roman Fort (Oltean, 2007)
The 5-day revisit period at the equator coupled with 13 spectral bands and a spatial resolution of $10 \mathrm{~m}$, makes the Sentinel-2 imagery a very powerful tool for monitoring and safeguarding the cultural heritage sites.

Anthropic activities are putting increasing pressure on the cultural heritage sites especially when these are situated in the close proximity or inside human settlements.

corresponding to an ancient road (CContains modified Copernicus Sentinel-2 data 2019)

Based on Landsat-8 imagery, a multi-temporal change analysis was performed using pan-sharpened images with spatial resolution of $15 \mathrm{~m}$. Figure 4 and Figure 5 present the human intervention within archaeological site limits represented by new building construction and agricultural activities.

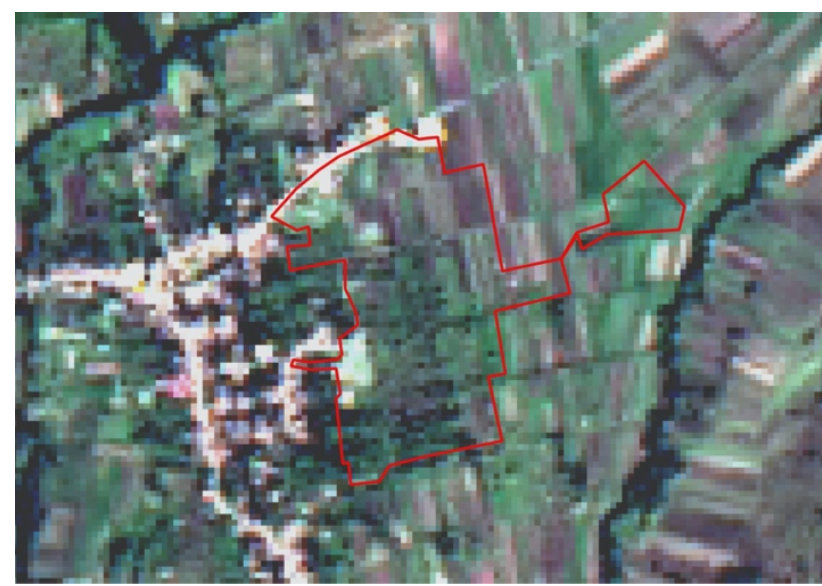

Figure 4. Ulpia Traiana Sarmizegetusa site limits overlaid on Landsat-8 image from 05.10.2013 (CContains modified Landsat-8 imagery)

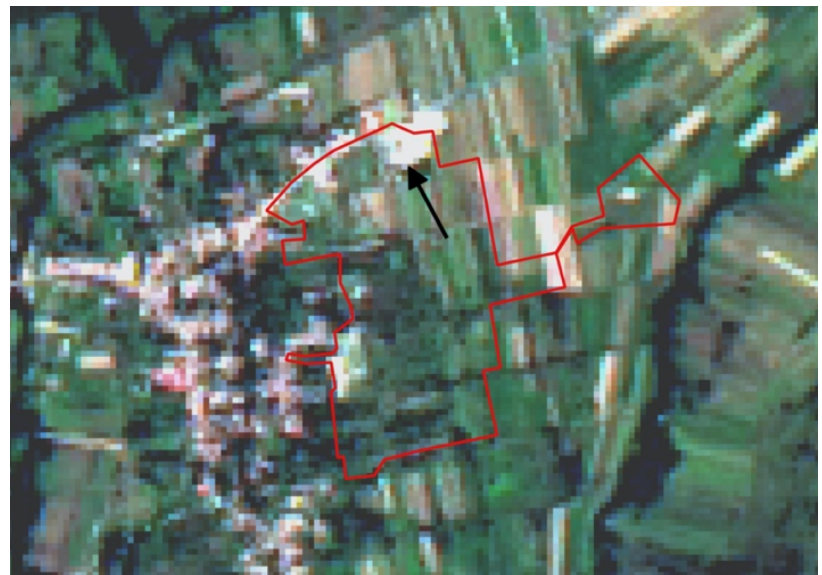

Figure 5. Ulpia Traiana Sarmizegetusa site limite overlaid on Landsat-8 image from 17.09.2018 (CContains modified Landsat-8 imagery)

In the case of Sarmizegetusa Ulpia Traiana, the village of Sarmizegetusa is situated near the archaeological remains of the ancient roman capital of Dacia province. In the past centuries, the foundations of the present-day village of Sarmizegetusa were placed on top of the ancient city and according to the historians, in some cases, the houses were built using construction materials extracted from the archaeological site. 


\subsection{Project 2: Nanotechnology - an innovative approach of developing materials and methods for cultural heritage safeguarding}

Satellite imagery can be used to assess the general environment conditions related to new archaeological findings. This kind of information is important in the first stages of the conservation procedures by providing a starting point for understanding the natural or anthropic characteristics of the newly found artefact's environment.

While geoinformatics offer relevant information about the environment, nanotechnology can be used for long-time protection of the retrieved artefacts. In the framework of the project, solutions based on nanotechnologies have been developed for protection against corrosive and fungal actions.

The current state of preservation for many of the historical monuments on the Romanian territory require strong measures to be taken to stop their degradation. One of the consequences of the degradation of the historical monuments due to various destructive factors (anthropic, microclimatic, biological, air pollution, etc.) is the loss of the physical-chemical-mechanical and aesthetic characteristics of the binding materials found in the structure of these monuments. Most of the cultural heritage objects in museums are kept for long time periods in storage space that should provide qualitative and long-lasting protection for artefacts.

Today, optimized recipes for nanomaterials are crucial for better conservation of cultural heritage objects with different support materials, paper or ceramics (Fierascu et al., 2020).

In the framework of this component project, laboratory studies in the field of nanotechnologies were performed in order to develop several recipes for the protection of the cultural heritage.

In order to maximize the effects of the processes of prevention, control, analysis and conservation of ceramic objects and materials, different techniques were used, including nuclear and radiographic techniques on bactericidal nanomaterials.

The project has developed methods for obtaining and characterizing the soft nanomaterials used in conservation and restoration. Fifteen solutions in isopropyl alcohol of 3 different concentrations were prepared of the soft synthesized nanomaterials. Tests on simulated and real ceramic artefacts were performed with the prepared solutions in order to evaluate, at different time periods, the physical-chemical interaction as well as in terms of the aesthetic and chromatic effects between the proposed recipes and the ceramic support material (Figure 6).

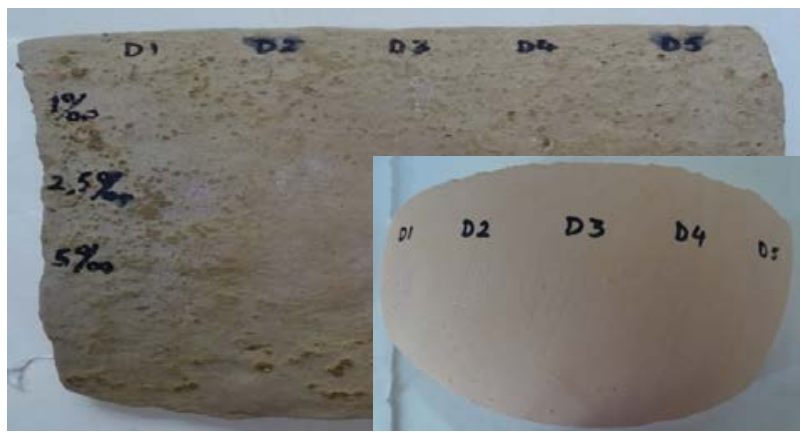

Figure 6. Recipes testing on real (back image) and simulated ceramic artefacts (front image)

The developed solutions were applied to the ceramic artefacts. The pottery from which the real artefact is made is semifinished and has, as a degreaser, fine sand with small grain and the type of paste is homogeneous. The object was made by a reducing combustion. Regarding the state of conservation, uneven mineral deposits and exfoliation were observed on its surface.

The conclusions that can be drawn so far regarding the behaviour of the solutions proposed for the first tests are favourable to the new product. It is observed that the ceramic fragments were not degraded, the covered surfaces did not become opaque, did not change their colour, did not become porous or glossy. In order to use the product in the restoration process, it has to be tested over a longer period in order to observe changes or transformations on the surface or inside the ceramic material.

Also, in order to stop the microbiologic attack on the paper artefacts, a non-invasive innovative nanomaterial recipe was created. The tests performed on several samples have shown very promising preliminary results (Figure 7).

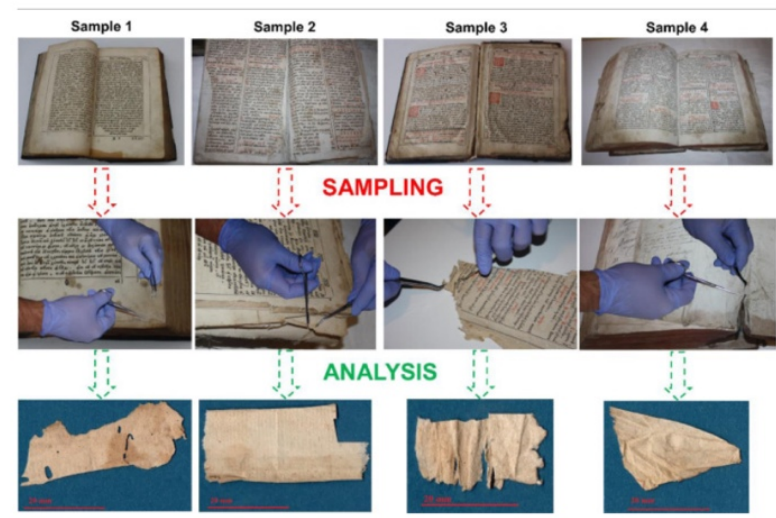

Figure 7. Recipes testing on real (top) and simulated paper artefacts (bottom)

\subsection{Project 3: Integrated cultural heritage management (conservation, restoration and protection)}

Numerous cultural heritage sites are threatened by natural and anthropic hazards such as flooding, erosion, urbanization and many others, that can irreversibly deteriorate the artefacts and objectives. For the management of the mobile cultural heritage, standard working procedures have been elaborated in order to implement the various conservation and restoration measures, but also inventory procedures by filling out identity cards of the objects studied. The preservation and restoration of artifacts is a complex process, which involves the use of suitable working methods. The restaurateur chooses the type of intervention, establishing the methodology appropriate for each object. The integrated procedures of inventory and conservation-restoration contain valuable information from a historical point of view and information on the state of conservation/restoration, but also small studies of the materials from the physical chemically point of view (Figure 8). In the following stages of the project implementation, selected objects will be digitalized for promoting the valuable pieces and for their preservation.

From a geomatic perspective, present-day methods of obtaining data and information about objects or phenomena use passive and active satellite sensors for complex surveillance, research and monitoring of the Earth's surface. Remote sensing technologies have already shown a great potential as an important tool for the protection and prevention of monuments and sites. 


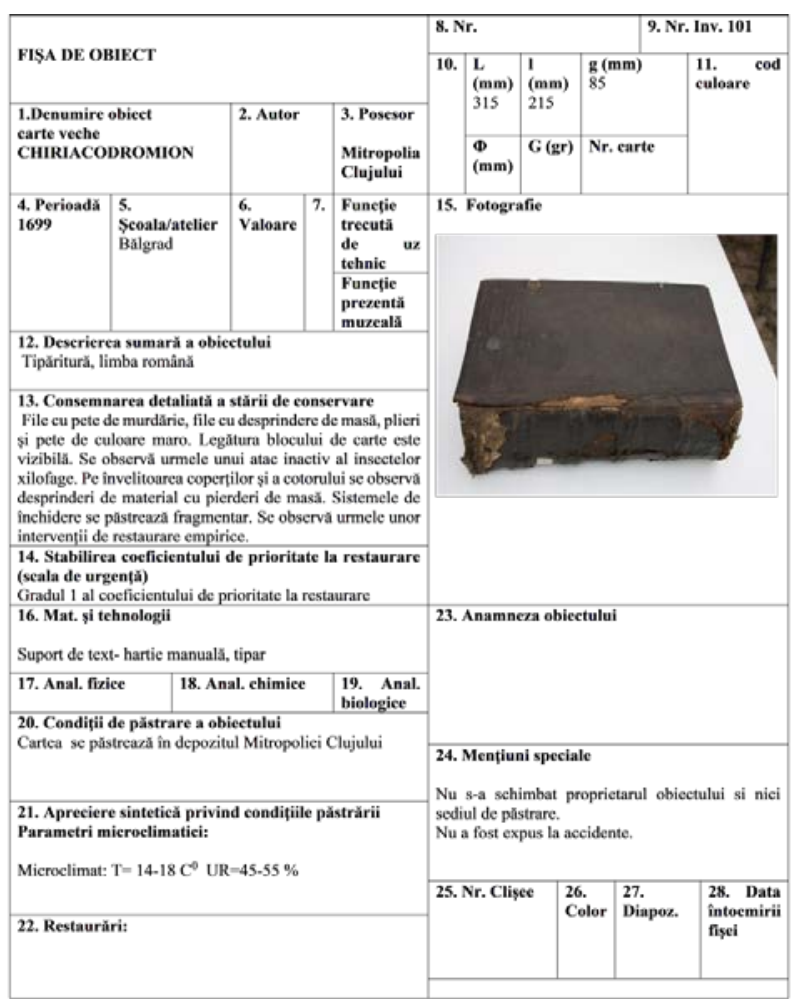

Figure 8. Example of an old book card

Geospatial products obtained by processing satellite imagery provide very useful information for monitoring $\mathrm{CH}$ archaeological sites. Advanced techniques such as PSInSAR (Permanent Scatterer Radar Interferometry) are commonly used today for satellite monitoring of buildings and other cultural heritage objectives. This technique represents a non-invasive method of monitoring the movements of buildings over time, significantly improving the management of these objectives and thus being able to avoid emergency situations regarding the structural integrity of these sites. Selected sites (Deva medieval fortress, Magna Curia Palace and Corvin Castle) were monitored using this technique to assess the condition of buildings and to prevent their deterioration. Using these methods of analysis, the vulnerable areas of the buildings can be identified with high precision and their evolution over time can be monitored.

For assessing urban expansion of Alba Iulia city (Figure 9), a satellite-based multi-temporal analysis was realized that covers the period 1926-2018. During the first 40 years of this time period (1926-1964), the city has roughly doubled its area, from $3 \mathrm{~km}^{2}$ to $7 \mathrm{~km}^{2}$ due to residential areas growth. In the following 25 years (1964-1989) the city has doubled again it's area to 14 $\mathrm{km}^{2}$ (driven by the industrial areas expansion) and then once more to $30 \mathrm{~km}^{2}$ in the last 20 years, generated by another increase in demand for residential spaces.

The fast urban sprawl has also generated an increase of the temperatures. The results of Land Surface Temperature (LST) analysis based on Landsat thermal infrared spectral bands, indicate that lower values are found in less developed urban areas, while in well-developed residential, commercial and industrial areas, the values are constantly higher, even by $5^{\circ} \mathrm{C}$. Nowadays, the cultural heritage conservation plans need to cope with increasing complex threats and pressures posed by the modern society. Remotely-sensed data are crucial for rapid and reliable repetitive assessments of cultural heritage sites and will play a more important role in the future for the consolidation of integrated management systems and procedures as these technologies are evolving very fast.

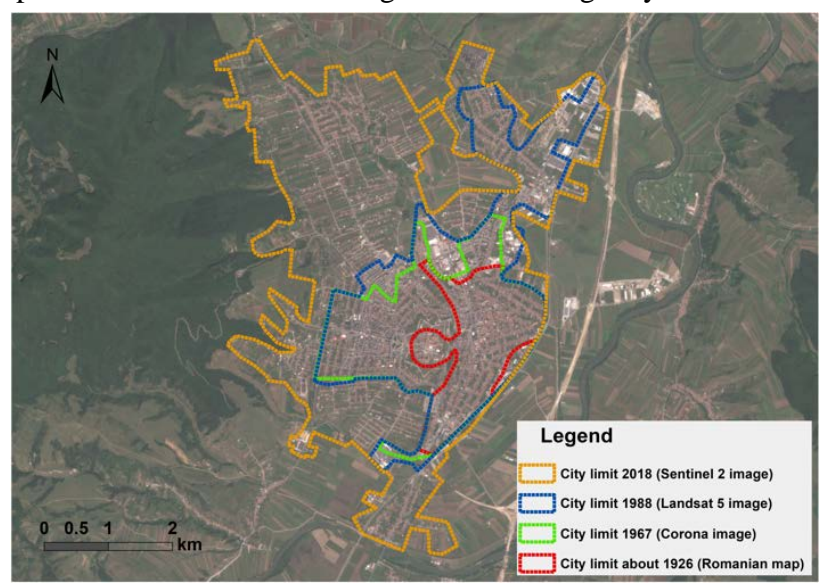

Figure 9. Alba Iulia urban sprawl (@Contains modified Copernicus Sentinel-2 data 2018)

\subsection{Project 4: Cultural heritage promotion based on modern technologies of digital reconstruction}

Digital reconstruction has a very good applicability in the field of cultural heritage, in works of conservation, restoration and rehabilitation of monuments and historical sites. Digital reconstruction represent an outstanding technology that is used for obtaining 3D replication of real objectives with detailed information. The most important reason for 3D reconstruction of $\mathrm{CH}$ is for digital documentation so that the structures or sites can be better preserved and monitored under impacts such as climate change, natural disaster and human exploitation (Fieber et al., 2017).

Pavlidis et al. (2007) reviewed non-contact methods for 3D digitization of cultural objects and monuments, including laser scanning, shape from structured light, photogrammetry and videogrammetry. Geoinformatics technologies, including photogrammetry, laser scanning, remote sensing, webmapping, and geospatial data science, have long played an important role in $\mathrm{CH}$ documentation and preservation (Barber et al., 2006; Levoy et al., 2000; Pieraccini et al., 2001; Remondino and Rizzi, 2010).

According to different application, photogrammetry has been applied to the recording and modelling of both small scale artefacts (Kersten and Lindstaedt, 2012) and large scale archaeological sites (De Reu et al., 2013). Unmanned aerial systems (UAS) have become a popular imaging platform for various $3 \mathrm{D}$ ground mapping.

For our case studies, the selected methods for digital reconstruction are Light Detection and Ranging (LiDAR) and photogrammetry. Both LiDAR and photogrammetry have their own advantages and disadvantages in the context of 3D reconstruction.

2.4.1 Study area: The Corvin Castle, also known as Hunyadi Castle or Hunedoara Castle is the most spectacular Gothicstyle castle in Transylvania, Romania. Today, the castle is a rare historical and architectural example. Built in the mid-15th century, Corvin Castle is split into three large areas: The Knight's Hall, the Diet Hall, and the circular stairways. Each of these three parts is surrounded by both circular and rectangular towers that were used for both defense and as a prison. For digital reconstruction of Corvin Castle, the selected technique was an integrated aerial mapping (Figure 10) based 
on the points determined by laser technology LiDAR for a detailed representation with high resolution and accuracy.

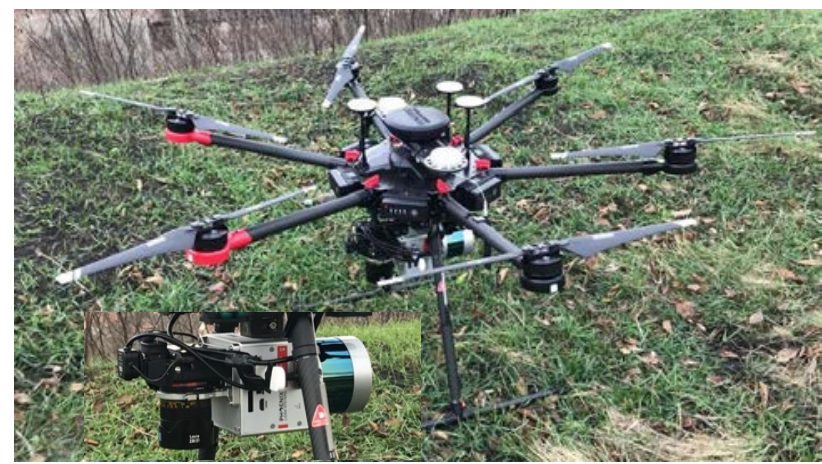

Figure 10. Integrated aerial mapping system

The Corvin Castle was scanned using a LiDAR Scout Sensor (Velodyne Ultra Puck VLP 32C) and a camera Sony A7R II, both mounted on a DJI Matrice M600 PRO UAV platform.

The first step was the setup of a specific acquisition plan suitable for building reconstruction. The plan was implemented during two flights over the castle, both in transversal and longitudinal trajectory. The flight altitude was set at $50 \mathrm{~m}$ and the density point was between 40 and 600 points on square meter. The aerial system also acquired 436 images.

2.4.2 Data processing: The processing of the recorded data was gradually performed during several stages in order to generate the point cloud: the trajectory, the geometric calibration parameters used in processing and the GNSS and Inertial Measurement Unit (IMU) data. The accuracy of the 3D model also depends on other factors like the fusion of LiDAR with optical data. LiDAR point cloud was supplemented with information of the RGB color value for each registered point which was assigned from the optical imagery.

In the case of an accurate digital reconstruction product, the final output depends on the quality improvement of acquired data and is correlated with the data volumes used. The LiDAR point cloud obtained after data fusion contains noise, which is abnormal data that must be identified and extracted (Figure 11).

LiDAR data processing involved the use of several software applications, either the one provided by Phoenix LiDAR Systems or commercial programs like Global Mapper and PIX4D Mapper.

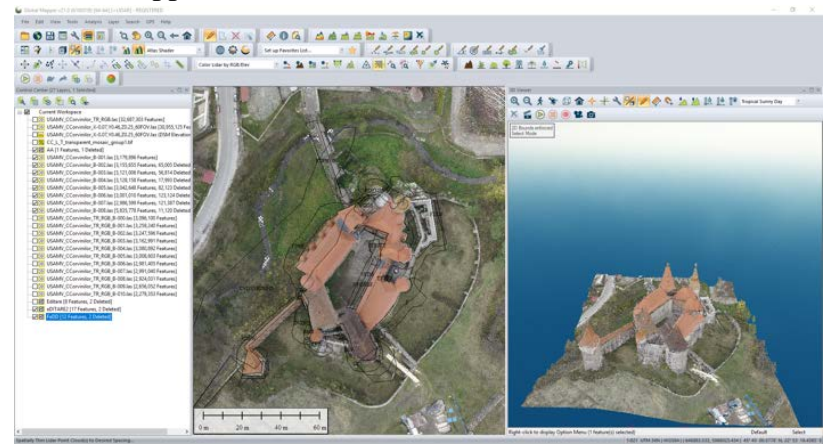

Figure 11. Corrections of LiDAR point clouds

Figure 12 presents the visualization of the $3 \mathrm{D}$ point cloud of high density. The 3D point cloud can be used to extract more important information such as high accuracy measurements of distances and surfaces.

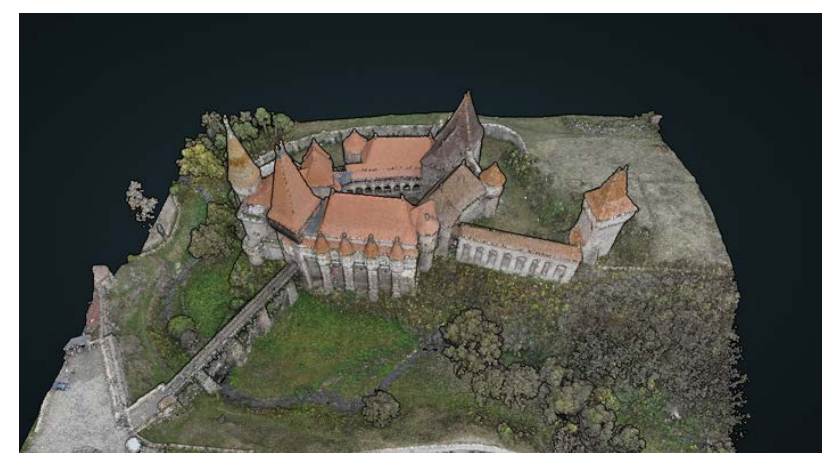

Figure 12. Visualization of the 3D point cloud

2.4.3 3D Model: The 3D reconstruction method was based on aerial images. In order to obtain dense and true-colour reconstruction of the castle, oblique images were captured.

The data processing has been performed in a number of steps to create a complete 3D model. After importing, the images were aligned into a single global system because the imagery was acquired from different viewpoints, therefore each one has its own coordinate system. This process is called registration or alignment. To improve the global accuracy, Ground Control Points (GCPs) are needed. In our case, GCPs were measured in the field using a GNSS receiver. The final stage of the processing has generated the mesh of the $3 \mathrm{D}$ model with its texture (Figure 13).

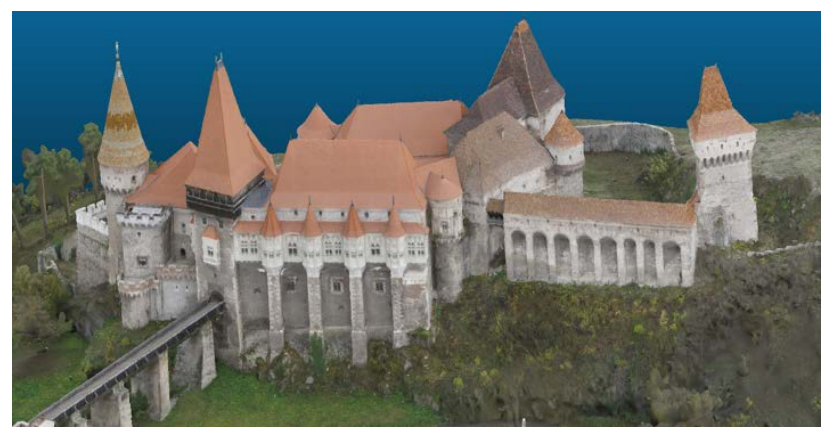

Figure 13. 3D Model of the Corvin Castel

2.4.4 3D Reconstruction of artefacts: A digital 3D artefact represents a digital replica of a real artefact that has resulted from a rigorous digitization process through the use of different equipment and processing methods (Neamţu et al., 2014).

The first step in creating a digital reconstruction for an artefact is the digitization process. The artefacts need to be carefully chosen. Figure 11a represents the case of a bronze ax from late period of the Bronze Age and was discovered in the Pianu de Jos archaeological site during the 2010 excavation campaign.

For the scanning process, the Artec Eva Lite handheld scanner was used. The processing of the data resulting from the scanning itself starts with aligning and reducing the errors between the scanned surfaces, this process being called fine registration.

The next important step is the global registration. The point clouds must be aligned into a common coordinate system. To cover the entire object, multiple scans from different angles are essential. Registration is the process in which all views and their corresponding coordinates are aligned into a single coordinate system.

Several steps are necessary to compose the 3D model:

- importing the scans and primary processing of each scan sequence (fine registration); 
- elimination of all scanned surfaces inherently, but not belonging to the object of interest (surface of the rotary table, etc.);

- aligning the individual scans;

- improving the quality of the assembled model (global registration);

- elimination of outliers (Figure 14b);

- processing of the final mesh from these individual scans (sharp fusion);

- reducing the number of polygons (mesh simplification);

- rendering the texture on the simplified model.

The result consists of a mesh that needs to be processed in order to obtain the texture of the artefact. Figure 14c illustrates the final output, the $3 \mathrm{D}$ reconstruction of the bronze ax.

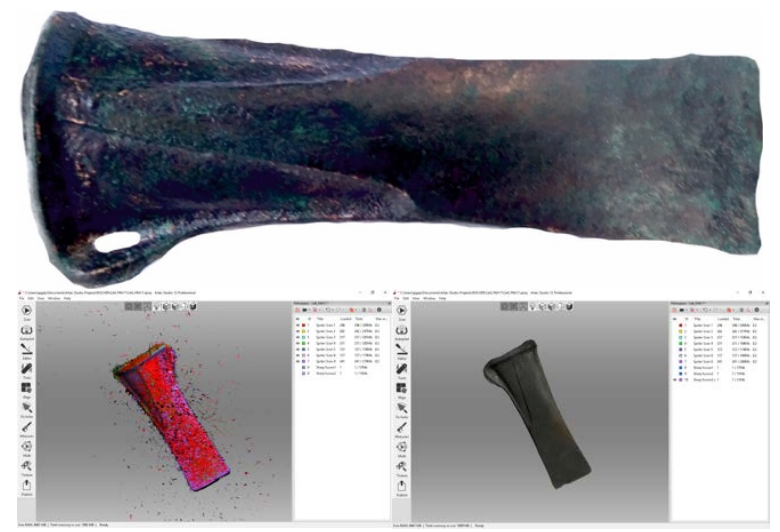

Figure 14. a) Bronze ax artefact (top); b) Aligned scans with the presence of outliers (bottom left); c) 3D Model (bottom right)

\section{CONCLUSIONS AND NEXT STEPS}

Within this project, an integrated approach of combining data obtained using different technologies has provided a complete documententation to safeguarding the cultural heritage. The jointly use of sattelite technologies, nanotechnology and classical methods of materials investigations has proven to represent an enhanced solution for conservation, restoration and protection of the cultural heritage. The long term monitoring of cultural heritage sites and their surrounding environment facilities the early recognition of potential risks. The investigations performed so far have detected the presence of underground structures of Micia fort and have documented anthropic hazards at Ulpia Traiana Sarmisegetusa. The human pressure on this archaeological site is on an ascending trend and is represented mainly by agricultural activities and urban growth inside the protected area of the site. Insufficient control measures and unclear site boundaries tend to amplify this phenomenon. The Persistent Scatterer Interferometry technique has been successfully applied for cultural heritage monitoring and the preliminary results for the Corvin Castle show uplift values up to $+7.70 \mathrm{~mm}$ /year in the north-eastern part of the building and negative values on the west side. 3D digital reconstruction plays a key role in order to promote the cultural heritage. In this sense, the integrated aerial mapping system equipped with LiDAR sensor collect significant data for obtaining accurate $3 \mathrm{D}$ point cloud and generating 3D digital model.

Monitoring the cultural heritage objectives with the support of space technologies, employing innovative techniques based on soft nanomaterials and promoting cultural heritage by using advanced digital reconstruction technologies brings a new multidisciplinary perspective to safeguarding the cultural heritage.

The complex project is set to be implemented by the end of 2020 and the results obtained so far are not completely validated. In fact, an important activity will be the correlation and the cross-validation of specific results obtained using different technologies related to similar targets.

Next steps of the implementation will imply the exploitation of very high spatial resolution optical and radar imagery for complete integration and fusion of these two types of satellite data. Another step will be to implement a pilot monitoring service for developing a protocol for the use of conservation recommendations for real artifacts using soft nano-materials and a practical guide will be developed for implementing the proposed monitoring solutions using space technologies.

The promotion of the complex project will be increased in the last stage of the implementation by developing printed and digital products like catalogues of significant objectives and artifacts and by creating virtual integrated environments.

\section{ACKNOWLEDGEMENTS}

This work was supported by a grant of the Romanian Ministry of Research and Innovation, CCCDI - UEFISCDI, project number PN-III-P1-1.2-PCCDI-2017-0413 / contract number 50PCCDI/2018, within PNCDI III.

\section{REFERENCES}

Agapiou, A., 2017. Remote sensing heritage in a petabytescale: satellite data and heritage Earth Engine $(\mathrm{C}$ applications. Int. J. Digit. Earth. https://doi.org/10.1080/17538947.2016.1250829

Agapiou, A., Alexakis, D.D., Sarris, A., Hadjimitsis, D.G., 2014. Evaluating the potentials of sentinel-2 for archaeological perspective. Remote Sens. https://doi.org/10.3390/rs6032176

Agapiou, A., Lysandrou, V., Alexakis, D.D., Themistocleous, K., Cuca, B., Argyriou, A., Sarris, A., Hadjimitsis, D.G., 2015. Cultural heritage management and monitoring using remote sensing data and GIS: The case study of Paphos area, Cyprus. Comput. Environ. Urban Syst. https://doi.org/10.1016/j.compenvurbsys.2015.09.003

Barber, D.M., Dallas, R.W.A., Mills, J.P., 2006. Laser Scanning for Architectural Conservation. J. Archit. Conserv. 12, 35-52. https://doi.org/10.1080/13556207.2006.10784959

Colesanti, C., Wasowski, J., 2006. Investigating landslides with space-borne Synthetic Aperture Radar (SAR) interferometry. Eng. Geol. 88, 173-199. https://doi.org/10.1016/j.enggeo.2006.09.013

Crosetto, M., Monserrat, O., Cuevas-González, M., Devanthéry, N., Crippa, B., 2016. Persistent Scatterer Interferometry: A review. ISPRS J. Photogramm. Remote Sens. 115, 78-89. https://doi.org/10.1016/j.isprsjprs.2015.10.011

De Reu, J., Plets, G., Verhoeven, G., De Smedt, P., Bats, M., Cherretté, B., De Maeyer, W., Deconynck, J., Herremans, D., Laloo, P., Van Meirvenne, M., De Clercq, W., 2013. Towards a three-dimensional costeffective registration of the archaeological heritage. J. Archaeol. Sci.

https://doi.org/10.1016/j.jas.2012.08.040 
Ferretti, A., Prati, C., Rocca, F.L., 1999. Permanent Scatterers in SAR Interferometry. SAR Image Anal. Model. Tech. II 3869, 139-145. https://doi.org/10.1117/12.373150

Fieber, K.D., Mills, J.P., Peppa, M. V., Haynes, I., Turner, S., Turner, A., Douglas, M., Bryan, P.G., 2017. Cultural heritage through time: A case study at Hadrian's Wall, United Kingdom, in: International Archives of the Photogrammetry, Remote Sensing and Spatial Information Sciences - ISPRS Archives. https://doi.org/10.5194/isprs-archives-XLII-2-W3-2972017

Fierascu, I., Fierascu, R.C., Stirban, A., Panaitescu, D.M., Nicolae, C.A., Raditoiu, V., Zgarciu, M.S., Leahu, A.C., 2020. Chemical and mineral characterization of Romanian book paper materials (XVII-XIXth century). Microchem. J. 152. https://doi.org/10.1016/j.microc.2019.104307

G., Diofantos., Agapiou, A., Themistocleous, K., D., D., Sarris, A., 2013. Remote Sensing for Archaeological Applications: Management, Documentation and Monitoring, in: Remote Sensing of Environment Integrated Approaches. https://doi.org/10.5772/39306

Geudtner, D., Torres, R., Snoeij, P., Davidson, M., Rommen, B., 2014. Sentinel-1 System capabilities and applications, in: International Geoscience and Remote Sensing Symposium (IGARSS). Institute of Electrical and Electronics Engineers Inc., pp. 1457-1460. https://doi.org/10.1109/IGARSS.2014.6946711

Kersten, T.P., Lindstaedt, M., 2012. Image-based low-cost systems for automatic 3D recording and modelling of archaeological finds and objects, in: Lecture Notes in Computer Science (Including Subseries Lecture Notes in Artificial Intelligence and Lecture Notes in Bioinformatics) https://doi.org/10.1007/978-3-642-34234-9_1

Levoy, M., Rusinkiewicz, S., Ginzton, M., Ginsberg, J., Pulli, K., Koller, D., Anderson, S., Shade, J., Curless, B., Pereira, L., Davis, J., Fulk, D., 2000. The digital Michelangelo project: 3D scanning of large statues, in: Proceedings of the ACM SIGGRAPH Conference on Computer Graphics.

Luo, L., Wang, X., Guo, H., Lasaponara, R., Zong, X., Masini, N., Wang, G., Shi, P., Khatteli, H., Chen, F., Tariq, S., Shao, J., Bachagha, N., Yang, R., Yao, Y., 2019. Airborne and spaceborne remote sensing for archaeological and cultural heritage applications: A review of the century (1907-2017). Remote Sens. Environ. 232, 111280. https://doi.org/10.1016/j.rse.2019.111280

Massonnet, D., Feigl, K.L., 1998. Radar interferometry and its application to changes in the earth's surface. Rev. Geophys. 36, 441-500. https://doi.org/10.1029/97RG03139

Navalgund, R., Rajani, M.B., 2017. The science behind archaeological signatures from space. Curr. Sci. 113, 1859-1872. https://doi.org/10.18520/cs/v113/i10/1859-1872

Neamţu, C., Popescu, D., Mateescu, R., Suciu, L., Hurgoiu, D., 2014. About quality and properties of digital artifacts. Mediterr. Archaeol. Archaeom. https://doi.org/10.5281/zenodo.13705
Oltean, I.A., 2007. Dacia: Landscape, colonization and romanization, Dacia: Landscape, Colonization and Romanization. https://doi.org/10.4324/9780203945834

Pavlidis, G., Koutsoudis, A., Arnaoutoglou, F., Tsioukas, V., Chamzas, C., 2007. Methods for 3D digitization of Cultural Heritage. J. Cult. Herit. https://doi.org/10.1016/j.culher.2006.10.007

Pieraccini, M., Guidi, G., Atzeni, C., 2001. 3D digitizing of cultural heritage. J. Cult. Herit. https://doi.org/10.1016/S1296-2074(01)01108-6

Remondino, F., Rizzi, A., 2010. Reality-based 3D documentation of natural and cultural heritage sitestechniques, problems, and examples. Appl. Geomatics. https://doi.org/10.1007/s12518-010-0025-x

Tapete, D., 2018. Remote sensing and geosciences for archaeology. Geosci. https://doi.org/10.3390/geosciences8020041 